\title{
Propagation Mechanism of Electrical Tree in XLPE Cable Insulation by investigating a Double Electrical Tree Structure
}

\author{
Xiaoquan Zheng \\ State Key Laboratory of Power Equipment and Electrical Insulation \\ Xi'an Jiaotong University, Xi'an, 710049, China \\ and George Chen \\ School of Electronics and Computer Science \\ University of Southampton, Southampton SO17 1BJ, UK
}

\begin{abstract}
This paper presents our experiments and analysis of the electrical tree growing characteristics. The relationship between electrical tree propagation and the material morphology in XLPE cable insulation has been studied by researching the structure and growth characteristics of a double structure electrical tree. It has been found that, due to the influence of uneven congregating state, difference in crystalline structure, and the existence of residual stress in semi-crystalline polymer, five types of electrical tree structures (branch, bush, bine-branch, pine-branch, and mixed configurations) would propagate in XLPE cable insulation. Three basic treeing propagation phases (initiation, stagnation, and rapid propagating phases) are presented in electrical tree propagating process. If initiation phase is very active, the single branch tree will propagate while if this phase is weak then the bush tree will occur more easily. There would be a clear double structure of electrical tree when it grows at submicroscopic structure uneven region of the material. A new parameter, the expansion coefficient is introduced to describe the electrical tree propagation characteristics. In addition, two other coefficients being used to describe our experimental results are dynamic fractal dimension and growth rate of electrical tree.
\end{abstract}

Index Terms - XLPE cable insulation, electrical tree structure, morphology; phase, mechanism

\section{INTRODUCTION}

ELECTRICAL tree is a type of electrical crack phenomena that occur in the polymer materials. It is named for its shape being similar to the nature trees. The electrical tree is a primary cause for the deterioration of electrical equipment (e.g. high voltage polymeric cables) whose main insulation is made of polymer. Once an electrical tree is initiated, it would grow splitting. Hence it is not permissible for such a tree to exist in high voltage insulation equipments. Since the 1950s after the electrical tree was first found in polymer insulation materials, many researches have been conducted [1-8], which provide great insight to the problem. However in our view, more work needs to be done for the following reasons: (1) The electrical tree is a complicated electro-erosion phenomenon and a consequence of several processes including charge injectionextraction, collision ionization, oxidation decomposition, partial discharge, partial high temperature, electro mechanical stress,

Manuscript received on 3 March 2007, in final form 18 December 2007. physics deformation, chemical decomposition, etc. The level of research relies not only on the human's understanding the tree, but also on the advancement of experiment instrument. For example, the relationship between electrical tree and space charge had not been known until the modern measurement technique on the space charge was developed. (2) Similar to gas discharge and the discharge in liquid, the randomness of electrical tree initiation and growth is the second distinctive feature. Because of the irrecoverably destroyed channel of electrical tree and the difference in submicroscopic physical structure of polymer, the treeing process in solid is much more complicated than that in liquid or gas. The appearance of the discharge channels can be very different in electrical trees grown using 'identical' samples and same experimental conditions, indicating the difficulty of research on treeing mechanisms. Sometimes the experimental data can only be a statistical result. (3) In the early research of the electrical tree, it was often assumed the material in study being homogeneous. In reality, the electrical characteristics of practical polymer 
insulation materials which have been used in high voltage equipments are somewhat influenced by many factors, such as filling material, morphology, crystalline state, mechanical stress, insulation thickness, environments etc, therefore, highly inhomogeneous. (4) The structure characteristics and mechanisms of electrical tree initiation and propagation vary with dielectric materials and their morphology. The electrical tree growth process in semi-crystalline polymer (such as polyethylene - PE or cross linked polyethylene - XLPE) is the most complicated in all materials. It is a well known fact that the tree can grow more easily along the electrically weak region around the boundary of a large crystal spherulite in insulation [1-4].

It is found that the shapes and the propagating characteristics of electrical tree in pure polymer are influenced by some combined factors: the micropore and residual mechanical stress in fragile dielectric material; the micropore and impurity in amorphous dielectric material; the crystallization slagging effect, the large crystal spherulite interfaces, the impurity concentration, and residual mechanical stress within semicrystalline dielectric material. In this paper, photographs taken during tree growing have been analyzed and the tree growth characteristic and the relationship between the growth characteristic of the electrical tree and XLPE morphological structure have been investigated by researching the structure characteristics of an electrical tree with double structures. Our research has indicated that the inhomogeneous crystallization, the high concentration of micropore and residual mechanical stress inside the insulation have a great influence on treeing characteristics of a dielectric material.

\section{EXPERIMENTS}

\subsection{SAMPLE}

All the samples were made from a commercial $66 \mathrm{kV}$ XLPE cable. The core of the cable was taken out, then, the cable insulation was cut into a series of pieces with a thickness of $5 \mathrm{~mm}$. The type of the electrode used in the present study was typical of needle-plate structure including two kinds of needle electrodes. One was steel with the radius of curvature being $5 \pm 1 \mu \mathrm{m}$ and the other was tungsten with the radius of curvature being $3 \pm 1 \mu \mathrm{m}$. The distance between the tip of high voltage electrode and the earth disk electrode was controlled around $3 \mathrm{~mm}$. In order to have a good contact between the needle electrode and the polymer, the needle was firstly cleaned in ethanol before its surface was coated with a thin layer of polyethylene. The needle was then inserted into the sample which has been softened by using a special heating mould.

A typical sample is shown in Figure 1. To produce residual mechanical stress within the XLPE sample to study the relationship between the characteristic of treeing and residual mechanical stress, the samples were cooled down using forced air flow at an approximate cooling rate of $10^{\circ} \mathrm{C}$ /min after mechanical stress was given during heating. The indirect sign that indicates the existence of the mechanical stress is appearance of an extrusion distortion in the brim of the samples (as shown in Figure 1b). It has been noticed that once the extrusion distortion shows up, the multicolor diffracted ripples are more likely to appear in the sample under a polarized microscope.
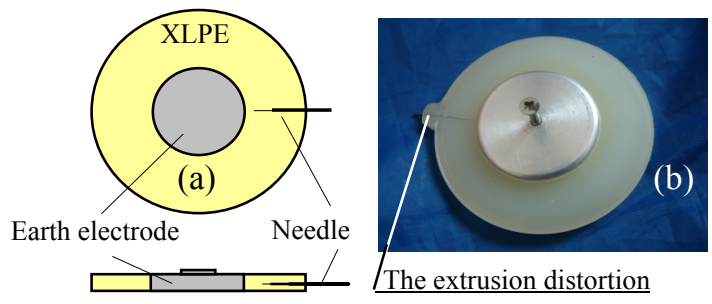

Figure 1. Sample of XLPE cable insulation

\subsection{EXPERIMENTAL SYSTEM}

The experimental system is shown in Figure 2 where the key components are a variable frequency high voltage generator that consists of a function generator and a high voltage amplifier with the maximum voltage output up to 20 $\mathrm{kV}$ peak and frequency range from dc to $3500 \mathrm{~Hz}$, a color digital camera, a set of computer system, a long focal-length microscope, and a motor driven X-Y stage localization system that is used to adjust the samples to a correct position. The advantage of this experiment system is that it can continuously take photos and record the length of the electrical tree while the tree is in propagation.

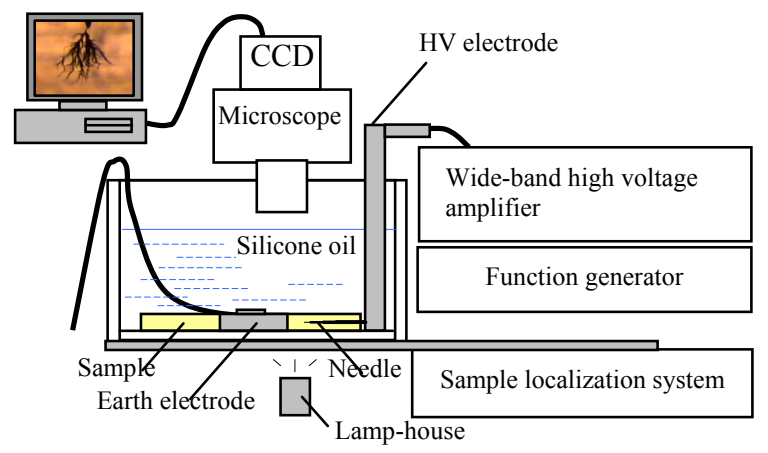

Figure 2. Sample and timing microscope CCD system

\section{EXPERIMENTAL RESULTS}

The experiments were performed at ambient temperature, in the range of 18 to $25^{\circ} \mathrm{C}$ using a sinusoidal waveform with a peak voltage of $20 \mathrm{kV}$.

The five representative photos in Figure 3 are selected from more than 400 pictures taken from our experiments. Two partially enlarged photos of the tree are also shown in Figure 3. Steel needle was used as high voltage electrode almost in all the experiments except the one in Figure 3e where tungsten needle was used. In the frequency range of 50 $\mathrm{Hz}$ to $2000 \mathrm{~Hz}$, when using the steel needle we a double structure electrical tree was observed only at frequency 250 $\mathrm{Hz}$ or below. The double structure trees can be seen in Figures $3 \mathrm{~b}, 3 \mathrm{c}$ and $3 \mathrm{e}$. In this double structure tree, the first part of the tree shows branch feature while the second part of the tree has one of the three types: pine-branch, bush-branch and bine-branch trees. When using the tungsten needle only 
one double structure electrical tree was observed and the second part tree structure shows bine-branch like at $2000 \mathrm{~Hz}$.

All the photos of electrical trees were taken from 40 plus samples. All the initial structures of the trees in our experiments have shown branch-shape without exception. This fact has revealed the similar initiation mechanism is in operation. The first part of the double structure electrical tree is always black branch-like or dense branch-like; however the second part is based on three basic structures (see Figures 3a, 3b, and 3c): bine-branch, pine-branch and bush. The binebranch and the pine-branch expand not only in all directions but also with some single branch structure (as shown in Figures $3 \mathrm{~d}$ and $3 \mathrm{e}$ ) and deviating from the direction of the applied electric field, where the bine-branch tree is much more remarkable because some single branch propagating nearly perpendicular to the direction of the applied electric field for a large distance compared to the original electrical tree branch that they initiate from (Figure 3e). Compared with the bine-branch electrical tree, the pine-branch is darker in color and lesser in expansion, indicating different propagation mechanisms between the two.

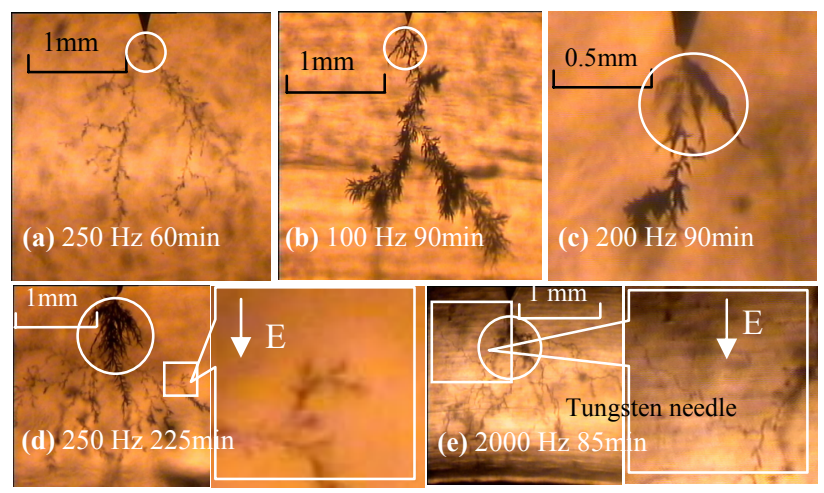

Figure 3. Three kinds of double structure of electrical tree and the partial characteristics of second structure

\section{DISCUSSIONS}

\subsection{THE GROWTH LAW AND CHARACTERISTICS OF ELECTRICAL TREE}

According to the experiment results, the multiplicity of the structures of electrical tree and the phase feature of the propagation process have been used to describe the growth characteristics of electrical trees in XLPE cable insulation.

\subsubsection{THE MULTIPLICITY OF ELECTRICAL TREE GROWTH}

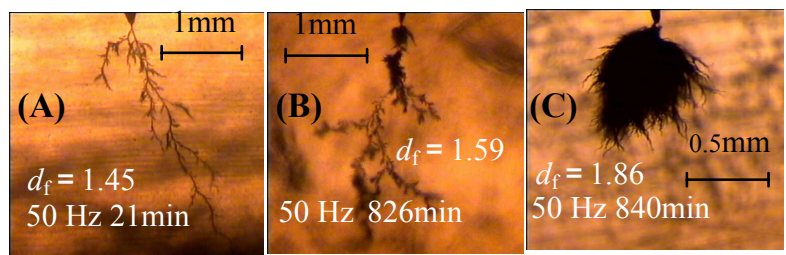

Figure 4. Three kinds of electrical tree in XLPE

The electrical tree that occurs in XLPE can be classified into three classes: the branch, the mixed configurations and the bush (as shown in Figures 4A, 4B, and 4C). The mixed configurations can be further divided into three types: the dense branch-pine tree, the dense branch-bine tree, and the dense branch-bush tree (the dense branch part has been signed with white circles in Figures $3 \mathrm{a}$ to $3 \mathrm{e}$ ).

\subsubsection{THE GROWTH PHASE FEATURE OF ELECTRICAL TREE}

Figure 5 shows the electrical tree length against time. The growth phase feature of electrical tree could be described by the growth rate characteristic. Figure $5 \mathrm{a}$ is a summary from experimental results while Figure 5 b combined with Table 1 shows the experimental results of propagation processes of electrical trees. The characteristic curves $A$ in Figure $5 b$ corresponds to the electrical tree propagation in Figure 4A, and the characteristic curves $\mathrm{B}$ and $\mathrm{C}$ in Figure $5 \mathrm{~b}$ correspond to the electrical tree propagation at the initial stage of treeing in Figures $4 \mathrm{~B}$ and $4 \mathrm{C}$. In fact, the length of the trees in Figures $4 \mathrm{~B}$ and $4 \mathrm{C}$ changes little from $100 \mathrm{~min}$ to $826 \mathrm{~min}$ and $840 \mathrm{~min}$ respectively. The experiment curve B in Figure $5 \mathrm{~b}$ corresponds to the branch pine-branch double structure in Figure $3 \mathrm{~b}$, while the experiment curves $\mathrm{A}$ and $\mathrm{C}$ in Figure $5 \mathrm{~b}$ represent a branch-bine-branch shape double structure and a branch-pine-branch shape double structure respectively. From the figure, one can see clearly that the phase feature of the growth rate shown in Figure 5 corresponds well to the propagating process of the electrical tree in Table 1, where the double structure of electrical tree goes through all the three growth phases.

Table 1. The propagation process of the double structure electrical tree.

\begin{tabular}{|c|c|c|c|}
\hline Item & \multicolumn{2}{|c|}{$\begin{array}{c}\text { The structure change of } \\
\text { electrical tree }\end{array}$} & \multirow[t]{2}{*}{ Characterization } \\
\hline Phase & In the process & In the end & \\
\hline $\begin{array}{l}\text { 1.Branch } \\
\text { initiation } \\
\text { phase }\end{array}$ & & & $\begin{array}{l}\text { (1) Charges injection } \\
\text { and extraction to } \\
\text { insulation from } \\
\text { needle, then electrical } \\
\text { tree is initiated. } \\
\text { (2) Single branch } \\
\text { structure initiating }\end{array}$ \\
\hline $\begin{array}{l}\text { 2.The } \\
\text { electrical } \\
\text { tree } \\
\text { stagnant } \\
\text { phase }\end{array}$ & & 14kn & $\begin{array}{l}\text { (1) Charges } \\
\text { injection and } \\
\text { extraction to } \\
\text { insulation from } \\
\text { conducting tree } \\
\text { (2) Dense and black } \\
\text { tree or bush } \\
\text { branch electrical } \\
\text { tree appears. }\end{array}$ \\
\hline $\begin{array}{l}\text { 3. The } \\
\text { double } \\
\text { structure of } \\
\text { electrical } \\
\text { tree } \\
\text { appearing } \\
\text { phase }\end{array}$ & & & $\begin{array}{l}\text { Pine-branch tree } \\
\text { initialization, Crown } \\
\text { of bines-branch tree } \\
\text { appears and grows } \\
\text { rapidly } \\
\text { The insulation would } \\
\text { been broken down } \\
\text { soon }\end{array}$ \\
\hline
\end{tabular}

In all of our samples, the initial structures of electrical trees are mostly branch shaped or approximating branch 
shaped structure with light gray color, but would gradually change into dark gray color of dense branch shaped structure during their slow propagation phase. If the tree propagates very fast then it would remain in branch shape and without changing color. This characteristic indicates that there are different propagation mechanisms and conducting features in these two kinds of tree channels. Figure 6 is the enlarged photos at the beginning stage of the tree propagation in Figure 4 (labels are the same as in Figure 4).

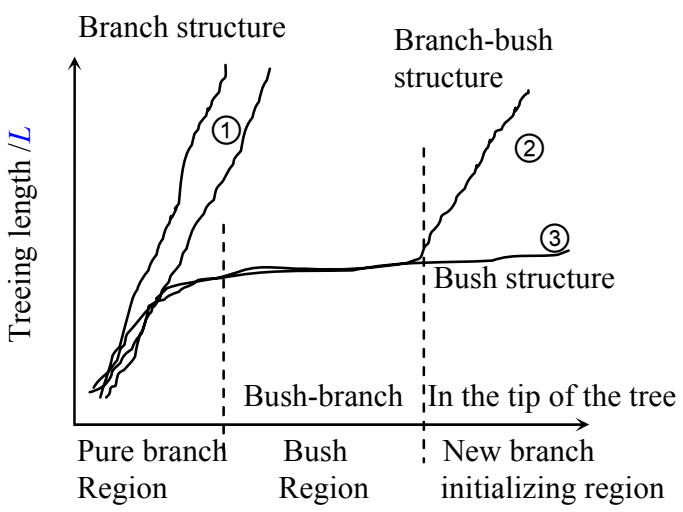

Electrical tree developing time $/ t$

(a)

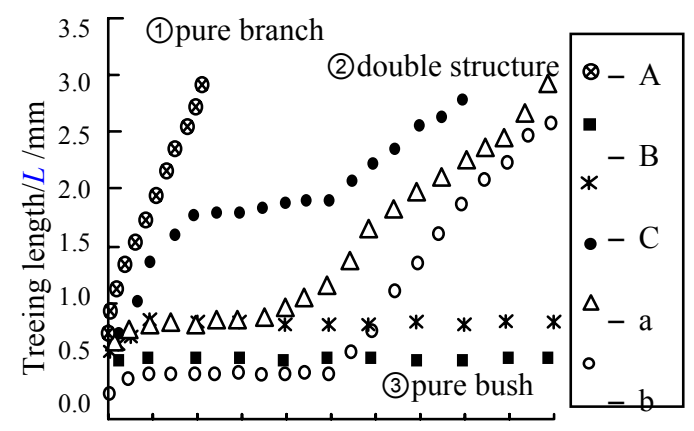

$\begin{array}{lllllllllll}0 & 10 & 20 & 30 & 40 & 50 & 60 & 70 & 80 & 90 & 100\end{array}$

Electrical tree developing time $t / \mathrm{min}$

(b)

(a) Summary of the relation between the growth speed and structure of electrical tree

(b) The relation between the growth speed and structure of electrical tree in experiments

Figure 5. The relationship between growing characteristics and structure of electrical trees

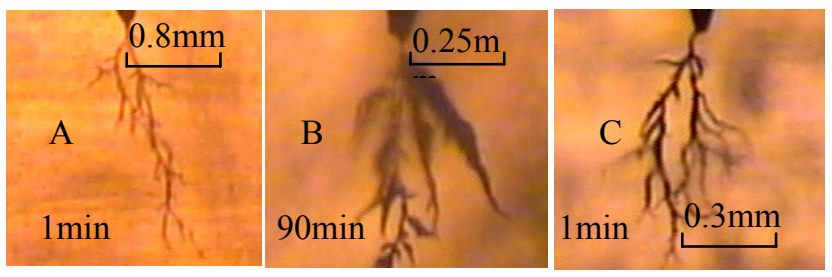

Figure 6. The early structure of electrical tree on Figure 4

In Figure 6B, it can be seen that PD in the channel has caused corrosion and carbonization along the wall of tree channel. But the initial branch shape can still be identified. The initial growth rate (see Figure 5) indicates that the tree initiation mechanism may be common for all the kinds of electrical trees that form in XLPE. Further details on electrical tree initiation mechanism can be found in references [1-2].

After the tree has been initiated the growth rate will either remain fast, resulting in the single branch structure observed in Figure 4A or decrease, entering a slow propagation phase. If this occurs many more filament corrosion channels will grow out from the initial branching structure and change the form of the tree from a branch to a bush or partial bush structure (as shown in Figures 4B and 4C). The behavior of the tree growth after the initial branching structure is closely related to the material morphology, the residual mechanical stress and the distribution of micropores [1-2].

\subsection{THE DYNAMIC CHARACTERISTICS OF THE ELECTRICAL TREE}

The dynamic characteristics of the tree have been described by using the dynamic characteristics of fractal dimension, and the new metric of the ratio of $\mathrm{D} / \mathrm{L}$ as below.

\subsubsection{THE RELATION BETWEEN FRACTAL DIMENSION CHANGE AND STRUCTURE DEVELOPMENT OF THE TREE}

Recently, a parameter named fractal dimension $\left(d_{\mathrm{f}}\right)$ was broadly introduced to describe the characteristic of electrical tree growth [5]. In fact $d_{\mathrm{f}}$ expresses the filling factor of the tree in its growth region. We using 'box-counting method [5] to describe the fractal dimension of the tree in our research and find that, the value of $d_{\mathrm{f}}$ varies from 1 to 2 for two dimension photo of the tree and is close to one when the tree is sparse branch like and will be close to two when it is bush like. For the trees in Figure 4, the value of fractal dimension is $d_{\mathrm{f}}=1.46$ for Figure $4 \mathrm{~A}, d_{\mathrm{f}}=1.59$ for Figure $4 \mathrm{~B}$, and $d_{\mathrm{f}}=1.86$ for Figure $4 \mathrm{C}$, respectively.

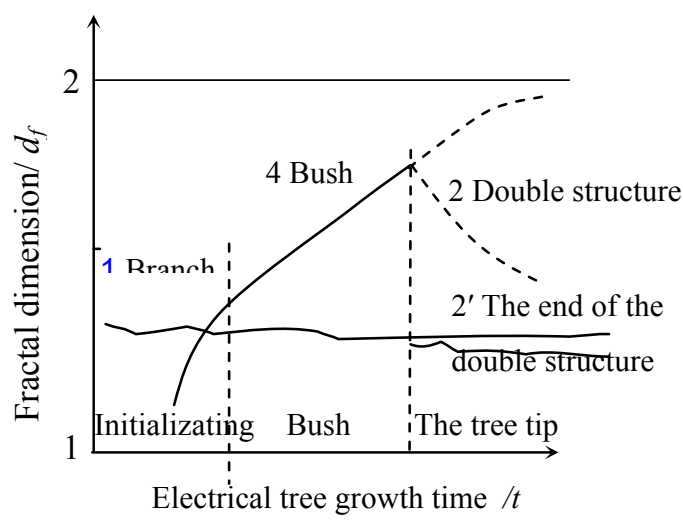

Figure 7. The relation between fractal dimension and structure of electrical tree

According to the variation of fractal dimension in the process of tree propagation as shown in Figure 7 (the relation between tree structure and fractal dimension), the variation of fractal dimension can be classified into three phases that correspond to the initiation of the branch of the tree, the formation of the bush tree, and the expansion of the tree tip, respectively. The value of fractal dimension is close to $d_{\mathrm{f}}=1$ 
at the beginning of electrical tree initiation. If the value of $d_{\mathrm{f}}$ in the course of the electrical tree initiation and growth varies little, the entire tree would be single branch shaped (curve 1 in Figure 7). When $d_{\mathrm{f}}$ of a tree continues to rise, it would be bush shape (curve 4 in Figure 7). When a few new branch burst from the tip of bush tee, the value of $d_{\mathrm{f}}$ would fall down rapidly (the region of the tree tip, curve 2 in Figure 7). It is worthy to be mentioned here is that the value of $d_{\mathrm{f}}$ would fall down to a very low level when it is used to describe only the tip region of pine-branch structure (shown as curve 2 ' in Figure 7).

\subsubsection{THE EXPANSION COEFFICIENT $(D / L)$}

In the course of our research it has become clear that it is not possible to define the growth behaviour of an electrical tree using a single parameter. For example, the growth speed can just express the electrical tree propagation along the direction of applied electric field, but cannot describe tree geometries where the tree has significant growth in directions other than that of the electrical field. The fractal dimension has difficulty in describing the geometries character of the mixed structure and the transverse expanding extent of the electrical tree. Hence, a new parameter, the expansion coefficient $D / L$, is proposed in this paper, where $D$ is the maximum width of the tree and $L$ is the maximum length of the tree. It has been found that there are several advantages using $D / L$ to describe the transverse expanding width of the double structure of electrical tree, and therefore $D / L$ can be used as a complementary parameter to other parameters.

Figure 8 shows the summarized variation characteristic of $D / L$ in the course of tree propagation, while Figure 9 shows actual experiment curves of $D / L$, where Figure 9a corresponds to the three kinds of electrical trees in Figure 4 (the signs have the same meaning as in Figure 4) and Figure $9 \mathrm{~b}$ corresponds to the trees in Figure 3 (the signs have the same meaning as in Figure 3). From these curves in Figure 9b it is clear that there is a very close relationship between the double structure of electrical tree and the three propagating phases of the trees. At the same time the increase in the applied voltage frequency could accelerate the growth rate of the double structure of the tree. For example, for the trees in Figure 3, one can see easily from Figure $9 \mathrm{~b}$ that the relationship between the growth slopes of the trees at different frequencies is: $K_{2000 \mathrm{~Hz}}>K_{250 \mathrm{~Hz}}>K_{100 \mathrm{~Hz}}$; and the ratio of the slopes of the growth speed of the trees is: $K_{2000}: K_{250}$ $: K_{100}=0.03: 0.012: 0.0067$. What must be explained here is that, curve (e) in Figure $9 \mathrm{~b}$ is corresponding to the tree in Figure $3 \mathrm{e}$ and this tree was obtained with the tungsten needle. The reason is that, the treeing in second propagation phase has nothing to do with the material and geometries of the needle.

\subsection{MECHANISM ANALYSIS}

\subsubsection{THE THREE TREEING PHASE IN XLPE CABLE INSULATION}

The propagation mechanism of the double structure of electrical tree is analyzed using Table 1 and Table 2 . In these two tables, the propagating process of the tree is divided into three phases. For clearity, in Table 2 we describe the parameter variation of the three propagating phases of the tree initiation, stagnancy and bine-branch, pine-branch shape appearance. The structure and conducting feature of the tree channel in each propagating phase are also

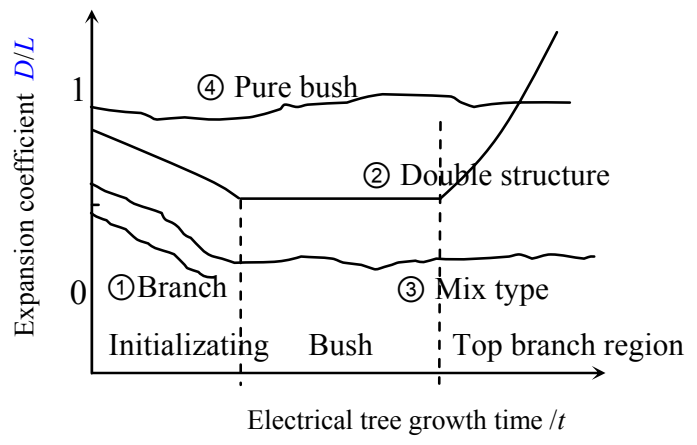

Figure 8. The relation conclude between expansion coefficient and structure of electrical tree

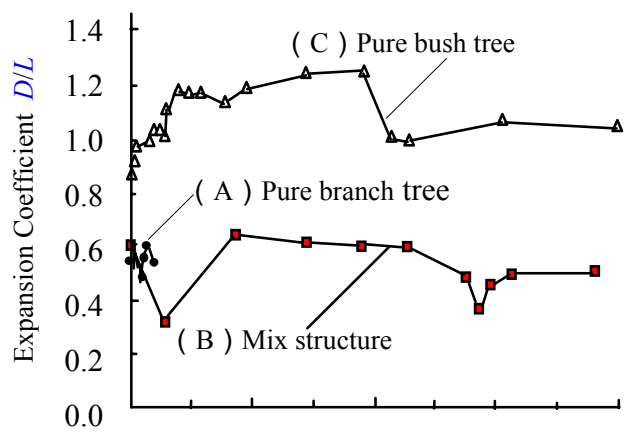

Electrical tree growth time $t / \mathrm{min}$

(a) The expansion law of three kinds of electrical tree

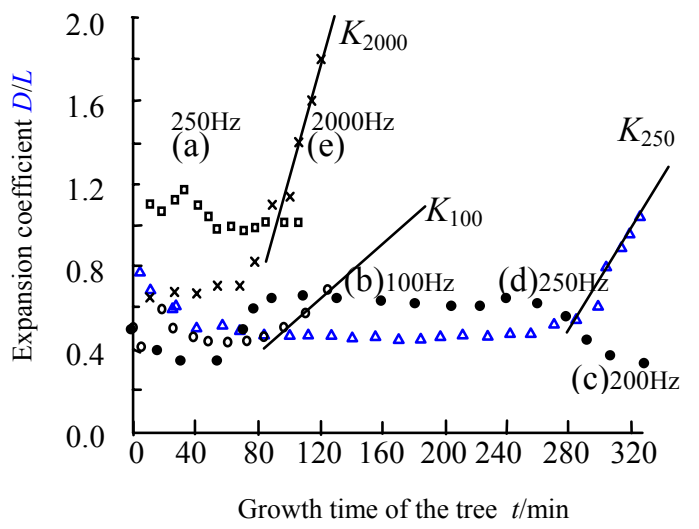

(b) The relationship between expansion coefficient and frequency

Figure 9. The relationship between expansion coefficient and structure of electrical tree

expressed in this table. It needs to be mentioned that, because the extent of charge injection into and extraction from insulation material by needle is determined by the insulation morphology around the needle area or the condition of weak point concentration, there is a significant scattering in the extent of the initiation phase of the electrical tree. In our 
experiments, the fastest electrical tree propagated at earth electrode in only 7 minutes. From $50 \mathrm{~Hz}$ to $1000 \mathrm{~Hz}$, the single branch electrical tree all occurred. Each of this single branch tree arrived earth electrode in 9 minutes $(1 \mathrm{kHz}), 7$ minutes $(100 \mathrm{~Hz}), 14$ minutes $(50 \mathrm{~Hz})$ and 21 minutes $(50 \mathrm{~Hz})$ respectively. The fact shows that the growth of electrical tree in this situation can be considered as a continuation of the tree initiation and as a result of energy relative concentration. If the depth of the original charge injection from the needle is shallow and the dielectric material is homogeneous, the channel of initial branch of electrical tree would change from insulation into semi-conducting and the structure of the tree would change into dense branch or bush-branch like in the course of long time PD, electro-erosion, and partial oxidative decomposition. In this situation, the color of the tree also will change from light gray to black gradually.

The reason for the times to breakdown in above mentioned single tree structure is not in order of the frequency. This may be related to the randomness of treeing process and the different branch density, but we can still find an approximate rule : the higher the frequency, the fast growth rate of the tree.

Table 2. Analysis of coefficient character, structure character, and mechanism in the process of electrical tree propagation.

\begin{tabular}{|c|c|c|c|c|c|}
\hline \multirow{2}{*}{$\begin{array}{l}\text { propagation } \\
\text { phases of the } \\
\text { tree }\end{array}$} & \multicolumn{3}{|c|}{ Parameter } & \multirow{2}{*}{ Mechanisms } & \multirow{2}{*}{$\begin{array}{l}\text { The character of the } \\
\text { electrical tree }\end{array}$} \\
\hline & $d_{\mathrm{f}}$ & $D / L$ & $L / t$ & & \\
\hline $\begin{array}{l}1 . \\
\text { Branch initiation } \\
\text { phase }\end{array}$ & 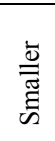 & & $\begin{array}{l}\dot{D} \\
.000 \\
.00\end{array}$ & $\begin{array}{l}\text { The electron injecting-eliciting from needle causes the region around the needle } \\
\text { to change to the low density along which the electrical tree propagates } \\
\text { because of } \mathrm{PD} \text {, charge recombination, and ionization by light etc. The tree } \\
\text { has character of insulating. }\end{array}$ & $\begin{array}{l}\text { The insulating } \\
\text { feature branch } \\
\text { electrical tree } \\
\text { propagating }\end{array}$ \\
\hline $\begin{array}{l}2 . \\
\text { The electrical tree } \\
\text { stagnant phase }\end{array}$ & $\Delta$ & 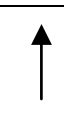 & & $\begin{array}{l}\text { PD reduction, electro-erosion and local decomposition lead to electrical tree } \\
\text { density increase. The channel of the electrical tree becomes conductive } \\
\text { gradually, causing charges to inject into or elicit from a wider region and } \\
\text { forming a more extensive electric weak district in the insulation. }\end{array}$ & $\begin{array}{l}\text { Changing into } \\
\text { semi-conducting } \\
\text { bush-branch electrical } \\
\text { tree }\end{array}$ \\
\hline $\begin{array}{l}3 . \\
\text { The double structure } \\
\text { of electrical tree } \\
\text { coming into being } \\
\text { phase }\end{array}$ & & 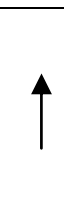 & $\hat{4}$ & $\begin{array}{l}\text { PD strengthening and the electrical tree expanding along the micropores on the } \\
\text { border of big crystal spherulite by partial high temperature and atmosphere } \\
\text { pressure. The bine-branch tree has a character of insulating and the pine- } \\
\text { branch tree has a character of semi-conducting. }\end{array}$ & $\begin{array}{l}\text { The insulating } \\
\text { bine-branch tree } \\
\text { expansion; } \\
\text { The semi-conducting } \\
\text { pine-branch tree } \\
\text { propagating. }\end{array}$ \\
\hline
\end{tabular}

In the third phase of the tree propagation, the primary reason that causes bine-branch to propagate broadly is that, at first, the semi-conducting dense branch or bush trees injection-extraction charge to dielectric insulation. This will lead the dielectric material in sub-microcosmic region to degrade continuously and cause resulting in a new PD. Then partial high temperature and pressure produced from PD will cause the wall in some micropores to be softened and burst between some micropores; this process will make some micropores be chained as a pearl string, therefore, the single branch tree [3-4]. This provides a feasible explanation for Figure $3 \mathrm{e}$, where a single branch propagates along the direction away from the applied electric field.

Of course, because of the local variation in crystalline structure, number of micro-voids, mechanical stress and impurity distribution, the sub-micro-defects in XLPE are also not uniform, this undoubtedly makes the second structure of the tree with different structures: some are bine-branch like, while the others with a shape of pine-branch or partial bush like.

\subsubsection{THE MICROPORES IN XLPE CABLE INSULATION}

It is well known that the coefficient of thermal expansion of PE is the biggest in all common use polymers [9]. In order to quantitatively analyze the number of the micropores in XLPE cable insulation, a simple calculation is shown below.
Assuming the insulation external diameter of a cable is $2 R$, the inner diameter of the cable insulation is $2 r$, and the coefficient of average linearity thermal expansion of XPLE is $\alpha$. When the outer layer of the cable insulation has been solidified and the volume is fixed in the cable manufacturing process, the volume of the micropores $\Delta \mathrm{V}$ caused by the inner layer solidifying and shrinkage is

$$
\begin{aligned}
& \Delta V=l \cdot \alpha \cdot \Delta t \cdot \pi\left\{\left(R^{2}-r^{2}\right)-\left[R^{2}(1-\alpha \cdot \Delta t)^{2}-r^{2}\right]\right\} \\
& \quad=l \cdot \pi R^{2} \alpha^{2} \cdot \Delta t^{2}(2-\alpha \cdot \Delta t)
\end{aligned}
$$

where $l$ is the length of cable and $\Delta t$ the temperature difference. Since $\alpha \cdot \mathrm{t}<<1$, equation (1) can be simplified to

$$
\Delta V \approx 2 l \cdot \pi(R \alpha \cdot \Delta t)^{2}
$$

Using the data of type YJAY110kV XLPE cable manufactured by Shen Yang Cable Manufacturer, Shen Yang, China as an example, the parameters are $r=11.3 \mathrm{~mm}$, $R=29.8 \mathrm{~mm}$ [10], and if we choose $\alpha=15 \times 10^{-5} / \mathrm{K}$ (the value of $\alpha$ for XLPE varies from $10 \times 10^{-5} / \mathrm{K}$ to $20 \times 10^{-5} / \mathrm{K}$ [9]), the temperature of the insulation extrusion to be $160{ }^{\circ} \mathrm{C}$ and the temperature after cooling to be $20{ }^{\circ} \mathrm{C}$, the percentage of the volume of the micropores occupied in XLPE cable insulation can be expressed as

$$
\begin{aligned}
\frac{\Delta V}{V} \times 100 \% & =\frac{2 l \pi(R \alpha \Delta t)^{2}}{l \pi\left(R^{2}-r^{2}\right)} \times 100 \% \\
& =\frac{2(R \alpha \Delta t)^{2}}{R^{2}-r^{2}} \times 100 \%=0.103 \%
\end{aligned}
$$


Assuming the micropores is a spherical with an average radius of $b=1 \mu \mathrm{m}$, the number of the micropore in a unit volume $\left(1 \mathrm{~cm}^{3}\right)$ of the cable insulation will be given as

$$
\begin{aligned}
& n / V=\frac{\Delta V / \Delta v}{V}=\frac{2 l \pi(R \alpha \Delta t)^{2}}{\frac{4}{3} \pi b^{3} \cdot l \pi\left(R^{2}-r^{2}\right)} \\
& =\frac{3(R \alpha \cdot \Delta t)^{2}}{2 \pi b^{3}\left(R^{2}-r^{2}\right)}=\frac{3 \times\left(2.98 \times 15 \times 10^{-5} \times 140\right)^{2}}{2 \pi \times\left(1 \times 10^{-4}\right)^{3}\left(2.98^{2}-1.13^{2}\right)} \\
& \approx 2.46 \times 10^{8}(\text { Number } / \mathrm{cm} 3)
\end{aligned}
$$

This result looks amazing. However, considering there is little shrinkage in the direction of cable length, the actual numbers of the micropore in XLPE cable insulation should be far more less than the calculated result in formula. Even so, for example, the true numbers of the micropore is several orders below the calculated value; the number of micropores is still fairly high. The above estimation is consistent with those published in literature [11]. It has been reported that volume ratio of macropore in XLPE cable insulation is $0.007 \sim 0.4 \%$. In addition there are some other reasons that lead to the formation of the macropores in XLPE cable insulation such as condensation of aromatic by-products of the initiator [12]. It is evident that the shrinking process is still one of main reasons that produce the micropores in XLPE insulation manufacture process.

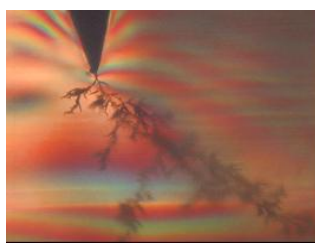

(a)

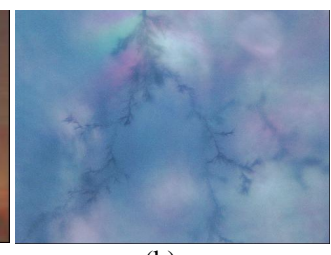

(b)
Figure 10. The residual mechanical stress and uneven crystalline in sample

It is obvious that micropore is one of the primary factors that weaken the cable insulation. Because the cooling process is from the outer layer to the inner after XLPE is extruded, the weakening factors, such as, the micropores, uneven crystallization and the residual mechanical stress, are all concentrated around the inner region of the cable insulation where the working electric field is maximal. In order to prove that the residual mechanical stress and the large crystal spherulite have significant effect on the propagation of the electrical tree, photos on the electrical tree propagation along the mechanical stress region (Figure 10a) and the boundary of the large crystalline spherulite (Figure 10b) have been taken by using the polarized microscope. Clearly, the micropores, non-homogeneous crystallization and the residual mechanical stress which concentrate around the inner region of the cable are the three important factors that cause the electrical tree to grow along the direction away from the applied electric field. The impact of this effect is more severe in the case of ultra-thick insulation, such as 220 kV XLPE cables or above. From reliability point of view, some measures, including research on the physical and chemical structure of the material and technology improvement on cable production, should be considered seriously.

\subsubsection{PARTIAL HIGH GAS PRESSURE AND HIGH TEMPERATURE IN TREEING}

The partial high gas pressure and high temperature produced by partial discharge in the tree channel is the main reason leading to the bine-branch tree propagation along the macropore concentration direction between crystalline and amorphous regions. It can be briefly analyzed as follows:

The degree of gas concentrated in the tree channel and the gasification energy are decided by partial discharge. The energy of a single pulse discharge can be expressed as

$$
w=\frac{Q U}{2}
$$

where $Q$ is the charge produced in the single pulse discharge and $U$ is the applied voltage. From this formula, we can estimate the gas volume $V_{0}$ produced assuming that the polymer in the tree channel is decomposed by the energy released from the single pulse discharge

$$
V_{0}=\frac{w}{w_{p}}=\frac{Q U}{2 w_{p}}
$$

where $w_{\mathrm{p}}$ is the gasification energy of the polymer with unit $\mathbf{J}$ $/ \mathrm{cm}^{3}$. The relationship between the maximum discharge $Q_{\mathrm{m}}$ of polyethylene and the length $L$ of the tree is

$$
Q_{\mathrm{m}}=\alpha L^{\beta}
$$

where $\alpha$ and $\beta$ are related coefficients.

Finally, the relationship between gas volume by discharge and the length $\mathrm{L}$ of gas gap can be expressed as

$$
V=\frac{\alpha U L^{\beta}}{2 w_{p}}
$$

The heat energy produced from partial discharge can make the material around the tree channel soften. Very high partial gas pressure leads to the tree channel propagation along the physical weakening area of XLPE - the micropores concentrate direction. Because the all direction of gas pressure, the propagating direction of the single branch of the bine-branch tree is barely effected by the direction of the applied electric field, this explains why the channel of the bine-branch tree propagates toward very broad direction, even deviating from the direction of the applied electric field.

Indirect evidence about the effect of partial high gas pressure and temperature on bine-branch tree is the intermittence propagating process of the tree. The short time stagnation of the tree growth rate is just about the gas pressure centralization and temperature rising process. After some boundary of micropores is broken through, the gas pressure is reduced and the next short time stagnation period of the tree growth starts. It is known from our experiments that short time stagnation period varies from several minutes to more than ten minutes. In addition, the growth rate of nonconducting bine-branch tree is quicker than conducting electrical tree. 


\section{CONCLUSIONS}

After analysis of the experimental results and discussion presented, the following conclusions may be drawn:

(1) The structure of electrical tree in XLPE insulation material can be classified into three categories. They are branch, bush-branch, and mixed-configurations. The mixedconfigurations could be further divided into three sub-types: branch-bush, branch-pine, and branch-bine, where branchpine and branch-bine are the result of uneven congregating state and defects such as micropores that concentrate on the inner region of cable insulation.

(2) The growth feature of the electrical trees in XLPE cable insulation can be expressed by three parameters. The three parameters are growth rate $L-t$, the fractal dimension $d_{\mathrm{f}}-t$, and expansion coefficient $D / L-t$. The parameter $D / L$ is first time defined in this paper and has unique advantages in describing mechanisms of the double structure of electrical tree.

(3) The initial insulation degradation is caused by the injection-extraction charges from electrode. The initiating mechanism of all kinds of electrical tree is common to that of the single branch tree propagation with the beginning shape as branch. PD corrosion, oxidization, chemical decomposition in the channel cause the branch tree with insulating character to change into dense-branch or bushbranch tree with the character of the semi-conducting. The charge injection-extraction from the tip of the dense-branch or bush-branch electrical tree into around insulation region, causes the material in the border of large crystal spherulite to be further degraded as micropores and impurity is also concentrated there. The bine-branch and pine-branch electrical tree will propagate very rapidly along this inhomogeneous region. The propagation of these two kinds of electrical tree is driven by PD in the main branch, the charge recombination, and luminescence-photonization, etc. Partial high temperature and pressure will be produced by all factors abovementioned and oxidation decomposition of material in the channel of the tree. Finally, the tree propagates and grows up along nearby micropore chains by partial high temperature and pressure.

(4) It is micropores, inhomogeneous crystallization, and residual mechanical stress that cause the insulation material around the core of XLPE cable to degrade seriously. This is a crucial problem that needs to be solved in manufacturing ultra high voltage XLPE cable with ultra-thick insulation.

\section{ACKNOWLEDGMENT}

The authors wish to thank the National Science Foundation of China under Projects No. 50577052.

\section{REFERENCES}

[1] L. A. Dissado, "Understanding Electrical Trees in Solid: From Experiment to Theory”, IEEE Trans. Dielectr. Electr. Insul., Vol. 9, pp. 483- 497, 2002.

[2] Y. Zhao, A. S. Vaughan, J. V. Champion, S. J. Dodd and S. J. Sutton, "The Structure of Electrical Trees In Semi-crystalline Polymers," Dielectric Materials, Measurements and Applications, IEE Conf. Pub. No. 473, pp. 314-319,2000
[3] Y. T. Wang, X. Q. Zheng, G. Chen and A. E. Davies, "Influence of Polymer Congregating state and Residual Mechanical Stress to Electrical Treeing in XLPE", Trans. China electro-technical Society, Vol.19 , No. 7, pp. 44-48, 2004. (In Chinese)

[4] X. Q. Zheng, G. Chen and A. E. Davies, "Conducting and NonConducting Electrical Trees in XLPE", Proc. of Chinese Society for Electrical Engineering (CSEE), Vol. 24, No.3, pp. 140-144, 2003. ( In Chinese)

[5] K. Kudo, "Fractal analysis of electrical trees", IEEE Trans. Dielectr. Electr. Insul., Vol. 5, pp. $713-727,1998$.

[6] J. V. Champion, S. J. Dodd, Y. Zhao, A. S. Vaughan, M Brown, A.E Davies, S. J. Sutton and S. G. Swingle, "Morphology and Growth of Electrical Trees in a Propylene/ethylene Copolymer", IEEE Trans. Dielectr. Electr. Insul. Vol. 8, pp. 284-292, 2001.

[7] J. V. Champion, S. J. Dodd, A. S. Vaughan, Y. Zhao and S. J. Sutton. "Effect of voltage, temperature and morphology on electrical treeing in polyethylene blends", Proc. Dielectric Materials, Measurement and Applications, London, Guildhall Univ, UK, IEE Conf. Pub. No. 473, pp. 35-40, 2000.

[8] Y. X. Zhou, X. G. Luo,. P. Yan, X. D. Liang, Z. C. Guan and N. Yoshimura, "Influence of morphology on tree growth in polyethylene", Intern. Sympos. Electr. Insulating Materials (ISEIM), Himeji, Japan, pp. 194-197, 2001.

[9] D. R. Xie and S. Z. Wu, "Physics of Macromolecular for Electrical Engineering”, Xian Jiaotong University Press, pp. 20-64, 1990. (In Chinese)

[10] Z. Y. Liu and H. M. Wang, "The Design Principle of Power Cable Structure", Xian Jiaotong University Press, pp.65-69, 1995.(In Chinese)

[11] T. Mizukami, K. Takahashi, C. Ikeda, N. Kato and B. Yoda, "Insulation properties of cross-linked polyethylene cable cured in inter gas", IEEE Trans. Power Apparatus and Systems, Vol. PAS-94, No. 2, Mar-Apr, pp. 467-472, 1975.

[12] J. Muccigrosso and P.J. Philips, "The morphology of Cross-Linked Polyethelene Insulation ", IEEE Trans. Electr. Insul., Vol. 13, pp. 172$178,1978$.

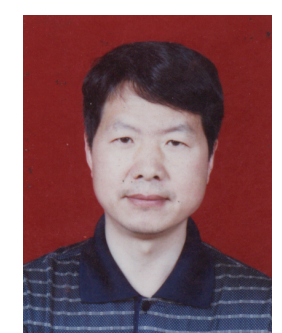

Xiaoquan Zheng, was born in China in 1954. He received the B.Eng., M.Sc. and Ph.D. degrees in electrical engineering from Xian Jiaotong University, China in 1982, 1990, and 2000 respectively. He was in Southampton University, UK as a Visiting Scholar from 2001 to 2002. He has been a Professor since 2007 in the Department of Electrical Engineering, Xian Jiaotong University and is engaged in research and teaching on the properties and measuring technology of dielectric materials and published over 50 papers.

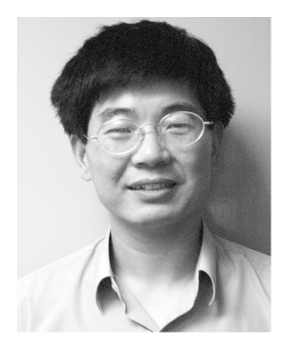

George Chen was born in China in 1961. He received the B.Eng. and M.Sc. in 1983 and 1986, respectively in electrical engineering from Xian Jiaotong University, China. After he obtained the $\mathrm{Ph} . \mathrm{D}$. degree in 1990 in electrical engineering from The University of Strathclyde, UK. He joined the University of Southampton as a postdoctoral research fellow and became a senior research fellow subsequently. In 1997 he was appointed as a research Lecturer and was promoted to a Reader in 2002. Over the years, he has developed a wide range of interests in high voltage engineering and electrical properties of materials and published over 100 papers. He is a visiting Professor at Xian Jiaotong University, China. 